\title{
PROPOSTA DE QUESTIONÁRIO PARA CARACTERIZAÇÃO DA PREVALÊNCIA DE SINTOMAS DIGESTIVOS NAS DOENÇAS DIFUSAS DO TECIDO CONJUNTIVO
}

\author{
Wellington M. MACHADO, Beatriz Funayama A. FREIRE, Oswaldo M. ROCHA, \\ Carlos Armando P. AZAMBUJA e Maria Elisa C. OLIVEIRA
}

\begin{abstract}
RESUMO - Racional - As doenças difusas do tecido conjunti vo afetam vários sistemas orgânicos, inclusive o digestório. Neste, as lesões variam em intensidade e freqüência na dependência da doença envolvida. A descrição das diferentes manifestações digestivas tem sido pouco frequiente, pouco detalhada e, não raro, baseada em experiências individuais e levantamentos retrospectivos. Tais formas de registro de dados produzem resultados muitas vezes conflitantes entre as diferentes casuísticas. Objetivo - Estabelecer de forma mais consistente, por intermédio de entre vista e questionário predefinido de sintomas, o conjunto e frequiência dos sintomas digestivos observados na esclerose sistêmica prog ressiva, artrite reumatóide, polimiosite/dermatomiosite, doença mista do tecido conjuntivo e lúpus eritematoso sistêmico. Pacientes e Método - Estudaram-se 99 pacientes, $90 \%$ mulheres, com idade média de 45 anos. Do total, 35 tinham ar trite reumatóide, 26 esclerose sistêmica prog ressiva, 21 lúpus eritematoso sistêmico, 12 der matomiosite/polimiosite e 5 doença mista do tecido conjuntivo. Todos foram submetidos, por investigador treinado, a entrevista e preenchimento de um questionário de sintomas digestivos, composto de 17 itens, previamente definidos. Resultados - O estudo revelou elevada prevalência de sintomas gastrointestinais nas cinco doenças investigadas, muitas vezes afetando mais de $50 \%$ dos casos. Chamou a atenção a presença significativa de sintomas negligenciados pela literatura como a incontinência fecal. Discordante de trabalhos anteriores, os pacientes desta série com artrite reumatóide apresentaram variadas queixas digestivas, surpreendendo o achado de disfagia em 1/3 deles. Conclusões - As doenças difusas do tecido conjuntivo são causas de freqüentes e numerosos sintomas digestivos. O uso de questionários predefinidos mostrou-se instrumento válido na identificação de substancial número de sintomas, alguns deles ainda não referidos pela literatura. Por fim, foi constatada escassez de trabalhos passados e atuais relativos às manifestações gastrointestinais das doenças difusas do tecido conjuntivo, o que prejudicou análises comparativas mais amplas.
\end{abstract}

DESCRITORES - Doença mista do tecido conjunti vo. Lúpus eritematoso sistêmico. Escleroderma sistêmico. Artrite reumatóide. Gastroenteropatias. Questionários.

\section{INTRODUÇÃO}

As doenças difusas do tecido conjuntivo (DDTC) são enfermidades de comprometimento imunológico e inflamatório que acometem diferentes sistemas orgânicos. O sistema digestório é comumente atingido e, embora na dependência do tipo de DDTC, o comprometimento seja mais direcionado para uma víscera ou outra, todas potencialmente podem ser lesadas ${ }^{(25,28,32)}$. Como consequiência, os sintomas variam de uma doença para outra em função do órgão mais acometido.
Essas características das DDTC geram imprecisões na descrição das suas manifestações digestivas, ag ravadas pelo fato de que o cadastramento de tais manifestações tem sido esparso e freqüentemente baseado em relatos de experiências individuais ou revisão de prontuários ${ }^{(8,17,22,24,36)}$. É bem conhecido, por outro lado, que informações colhidas desta forma sofrem numerosas influências, alterando a uniformidade e confiabilidade dos achados obtidos. Dentre as interferências mais comuns, ressalta-se o papel do indivíduo que coleta a informação. Dependendo do seu treino, cabedal de

Departamento de Clínica Médica da Faculdade de Medicina de Botucatu, Universidade Estadual Paulista - UNESP, Botucatu, SP.

Endereço para correspondência: Dr. Wellington M. Machado - Departamento de Clínica Médica - Faculdade de Medicina de Botucatu - 18618-000 - Botucatu, SP.

E-mail: wmachado@fmb.unesp.br 
conhecimentos, nível de interesse, inspiração momentânea na formulação das questões, os dados recolhidos poderão ser mais ou menos representativos e fiéis. Para obtenção de infor mações apropriadas é, portanto, relevante alguém especif icamente treinado e motivado para a tarefa, apto a realizar entrevista bem orientada e, se possível, fazendo uso de questionário preestabelecido, a ser aplicado uniformemente aos entrevistados. Seguindo-se essas normas, muitas das falhas acima apontadas poderão ser minimizadas e um rol de sintomas mais completo assegurado.

O presente estudo teve por objetivo catalogar os sintomas digestivos mais freqüentes na esclerose sistêmica progressiva (ESP), lúpus eritematoso sistêmico (LES), artrite reumatóide (AR), polimiosiosite/dermatomiosite (PM/DM) e doença mista do tecido conjuntivo (DMTC), a partir de entrevista com pacientes acometidos por essas afecções, realizada por gastroenterologista previamente treinado em coleta de dados referentes àquelas doenças e usando como roteiro uma ficha clínica contendo questionário predefinido dos sintomas gastrointestinais a serem pesquisados. A intenção do trabalho é aperfeiçoar a confiabilidade e reprodutibilidade dos resultados alcançados e estabelecer um perfil sintomático mais consistente para as DDTC.

\section{PACIENTES E MÉTODO}

O trabalho constou de duas fases: a primeira chamada piloto e a segunda, definitiva.

\section{Fase piloto}

Esta fase teve como objetivo testar preliminar mente a idéia da exis tência de discordância entre dados colhidos por intermédio do levantamento de prontuários médicos e aqueles resultantes de coleta por meio de questionário e entrevista. A partir de uma lista de portadores de DDTC do Hospital das Clínicas de Botucatu, SP, 14 pacientes foram selecionados aleatoriamente e a seguir convocados para entrevista e preenchimento do questionário de sintomas com um gastroenterologista. A pesquisa da ocor rência de sintomas foi restringida ao período de 1 ano e meio anterior à aplicação do questionário, salvo quando havia sintomas extremamente marcantes fora dele. $\mathrm{O}$ mesmo questionário foi a seguir completado, a partir dos sintomas registrados no prontuário, ao longo das várias consultas pelas quais o paciente passara anteriomente.

\section{Fase definitiva}

Nesta fase, foram incluídos indivíduos com diagnóstico fimado de DDTC e sem outra afecção com repercussão no sistema digestório capaz de confundir os resultados. Esta última condição implicou na eliminação de 20 dos 119 pacientes inicialmente selecionados para o estudo. Concluída a etapa de diagnóstico e seleção, os pacientes foram encaminhados ao gastroenterologista para entrevista com relação aos sintomas digestivos. Nesta entrevista, foi usada como roteiro de perguntas uma ficha clínica igual à utilizada na fase piloto, constando dos dados demográficos e diagnósticos dos pacientes e um questionário composto de 17 questões, em que as opções de respostas eram: sim (S), não (N) ou não conclusiva ou duvidosa (NC). As questões englobavam um conjunto abrangente de sintomas associados a diferentes alterações do sistema digestório. Constava ainda de um item sobre a concomitância de outras doenças crônicas (Figura 1).

Considerando a freqüente confusão no entendimento da terminologia utilizada pelos médicos, particularmente obscura para o paciente com limitado nível de instrução que constitui a maioria da clientela desta série, algumas medidas cautelares foram tomadas. Isto incluiu a criação de ambiente descontraído na entrevista, uso de palavras simples e populares sobre os motivos da consulta e do significado de cada sintoma pesquisado e a elucidação das dúvidas apresentadas pelo entrevistado. Só após o cumprimento desses itens é que se passava à entrevista propriamente dita. A todos os envolvidos era informado que o interesse da pesquisa era circunscrito a queixas/ sintomas de caráter crônico, presentes no último ano e meio. Portanto, episódios fortuitos ou passageiros não foram incluídos, salvo fatos particularmente marcantes relatados pelo entrevistado e aceitos como tal pelo entrevistador. Quanto à fixação do prazo limite de 1 ano e meio, a intenção foi atenuar as distorções de memória que se ampliam quanto mais retroativo é o período investigado. Finalmente, foram omitidas perguntas específicas sobre o acometimento do fígado e pâncreas por serem manifestações menos freqüentes.

Dos 99 pacientes entrevistados, 35 tinham diagnóstico de AR, 26 de ESP, 21 de LES, 12 de PM/DM e 5 de DMTC. Tais diagnósticos foram baseados nos critérios internacionais recomendados. Nos portadores de AR, a idade média foi de 46,48 ( $\mathrm{DP} \pm 18,78$ ), 27 eram mulheres. Na ESP a idade média foi de 48,6 anos (DP \pm 14,4), 25 mulheres. $\mathrm{Na}$ PM/DM a idade média foi de 42,16 anos ( $\mathrm{DP} \pm 15,2$ ), todas mulheres. No LES a idade média foi de 39,7 anos (DP \pm 13,9), $20 \mathrm{mu}-$ lheres. Na DMTC a idade média foi de 47,4 anos (DP $\pm 14,4$ ), 4 mulheres. Quatro casos de ESP apresentavam a forma Crest. Vinte e três casos de fenômeno de Raynaud foram registrados, dos quais 20 associados à ESP, 2 à DMTC e 1 ao LES.

Todos os pacientes submetidos ao questionário foram previamente informados a respeito do protocolo de pesquisa e consentiram em dele participar.

\section{RESULTADOS}

\section{Fase piloto}

Os resultados da fase piloto acham-se dispostos na Tabela 1 , compreendendo diagnósticos, número de sintomas observados a par tir 
Machado WM, Freire BFA, Rocha OM, Azambuja CAP, Oliveira MEC. Proposta de questionário para caracterização da prevalência de sintomas digestivos nas

\section{DDTC x sintomas digestivos}

\section{QUESTIONÁRIO}

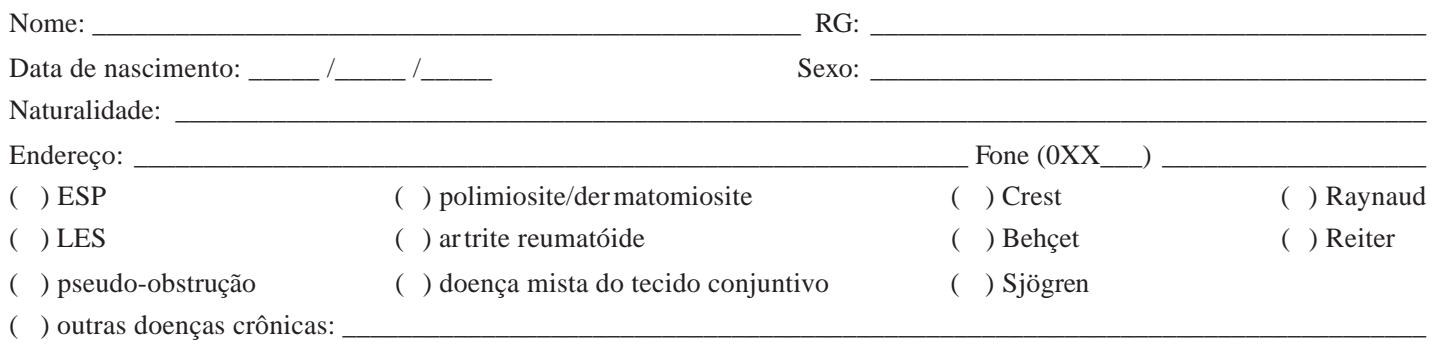

\begin{tabular}{|l|l|l|l|}
\hline \multicolumn{1}{|c|}{ Órgãos comprometidos } & S & N & NC \\
\hline Pele & & & \\
\hline Vasos & & & \\
\hline Músculos & & & \\
\hline Pulmões & & & \\
\hline Coração & & & \\
\hline Rins & & & \\
\hline Sistema nervoso & & & \\
\hline Outros & & & \\
\hline
\end{tabular}

\begin{tabular}{|l|l|l|l|}
\hline \multicolumn{1}{|c|}{ Sintomas } & \multicolumn{1}{c|}{ S N } & NC \\
\hline Engasgo & & & \\
\hline Disfagia & & & \\
\hline Odinofagia & & & \\
\hline Regurgitação & & & \\
\hline Pirose & & & \\
\hline Náuseas & & & \\
\hline Vômitos & & & \\
\hline Saciedade & & & \\
\hline Plenitude/empachamento & & & \\
\hline Azia & & & \\
\hline Estufamento/meteorismo & & & \\
\hline Dor abdominal & & & \\
\hline Íleo adinâmico & & & \\
\hline Má absorção & & & \\
\hline Diarréia & & & \\
\hline Constipação & & & \\
\hline Incontinência fecal & & & \\
\hline
\end{tabular}

$\mathrm{S}=\operatorname{sim} ; \mathrm{N}=$ não; $\mathrm{NC}=$ não conclusivo, duvidoso

FIGURA 1 - Questionário utilizado na entrevista dos pacientes

do levantamento de prontuários e da entrevista/questionário. Do total de 14 casos levantados, em nenhum coincidiu o número total de sintomas observados pelos dois métodos. Em 13, o questionário identificou número bem mais expressivo de sintomas que os registrados no prontuário, variando de 1,3 a 8 vezes mais. Tais resultados reforçaram a idéia da maior precisão do método entre vista/ questionário no estabelecimento da prevalência de sintomas digestivos nas DDTC. 
TABELA 1 - Diagnósticos e o número de sintomas digestivos detectados por meio do levantamento de prontuário e da entrevista-questionário

\begin{tabular}{lccc}
\hline Casos avaliados & Diagnóstico & $\begin{array}{c}\text { Número de sintomas por } \\
\text { levantamento de prontuário }\end{array}$ & $\begin{array}{c}\text { Número de sintomas por } \\
\text { entrevista-questionário }\end{array}$ \\
\hline Caso 1 & AR & 0 & 4 \\
Caso 2 & AR & 4 & 10 \\
Caso 3 & ESP & 7 & 12 \\
Caso 4 & ESP & 7 & 4 \\
Caso 5 & ESP & 2 & 12 \\
Caso 6 & ESP & 9 & 12 \\
Caso 7 & ESP & 5 & 14 \\
Caso 8 & PM/DM & 1 & 8 \\
Caso 9 & PM/DM & 2 & 6 \\
Caso 10 & PM/DM & 2 & 4 \\
Caso 11 & DMTC & 3 & 4 \\
Caso 12 & LES & 1 & 6 \\
Caso 13 & LES & 5 & 7 \\
Caso 14 & LES & 7 & 8 \\
\hline
\end{tabular}

\section{Fase definitiva}

Os resultados da prevalência de sintomas digestivos em 99 pacientes com DDTC investigados por intermédio de questionário predefinido, acham-se expostos na Tabela 2.

\section{DISCUSSÃO}

Nas DDTC, o aparato neuromuscular do sistema digestório pode sofrer importantes alterações no funcionamento, ocasionando o aparecimento de sintomas de grau variado de severidade, oscilando

TABELA 2 - Percentual de presença de cada sintoma conforme a doença estudada

\begin{tabular}{|c|c|c|c|c|c|}
\hline Sintomas & $\operatorname{ESP}(\%)$ & PM/DM (\%) & $\operatorname{LES}(\%)$ & DMTC (\%) & $\operatorname{AR}(\%)$ \\
\hline Engasgo & 23 & 75 & 14 & 60 & 8,5 \\
\hline Disfagia & 65 & 50 & 33 & 60 & 31 \\
\hline Odinofagia & 35 & 33 & 24 & 0 & 6 \\
\hline Regurgitação & 54 & 42 & 52 & 60 & 20 \\
\hline Pirose & 85 & 58 & 57 & 60 & 31 \\
\hline Náusea & 19 & 33 & 62 & 20 & 8,5 \\
\hline Vômito & 19 & 25 & 9,5 & 0 & 8,5 \\
\hline Saciedade & 38 & 8 & 48 & 20 & 17 \\
\hline Plenitude/empachamento & 42 & 42 & 62 & 40 & 31 \\
\hline Azia & 46 & 42 & 43 & 0 & 26 \\
\hline Estuf amento/meteorismo & 31 & 58 & 19 & 40 & 14 \\
\hline Dor abdominal & 23 & 8 & 33 & 20 & 28,5 \\
\hline Íleo adinâmico & 4 & 0 & 0 & 0 & 0 \\
\hline Má absorção & 0 & 0 & 0 & 0 & 0 \\
\hline Diar réia & 11,5 & 8 & 28,5 & 20 & 3 \\
\hline Constipação & 35 & 42 & 28,5 & 0 & 37 \\
\hline Incontinência fecal & 27 & 0 & 19 & 20 & 3 \\
\hline
\end{tabular}


entre simples azia na $\mathrm{AR}^{(1,13)}$, até disfagia com aspiração na $\mathrm{PM} /$ $\mathrm{DM}^{(6,23)}$ e refluxo gastroesofágico grave e Barrett na $\operatorname{ESP}^{(5,14,15,18)}$. Sur preendentemente, contudo, a despeito da variedade de tais achados, não há abundância de estudos que abordem em detalhe a prevalência dos sintomas, seu grau de severidade e distribuição nas diferentes DDTC. De que se dispõe, são publicações esparsas, a maioria resultante de revisões de prontuários ${ }^{(7,24)}$, li vros-textos ${ }^{(21,32)}$ e experiências pessoais $^{(3,22)}$, ou então, trabalhos sobre $\mathrm{f}$ isiopatologia das lesões e sua correlação com sintomas e procedimentos diagnósticos ${ }^{(8,10,12,16)}$. O conhecimento mais apurado da epidemiologia e quadro clínico de uma doença é, no entanto, essencial para que ela possa ser melhor diagnosticada e tratada.

Na primeira fase do presente estudo, ficou evidenciado o fato já referido por outros, da grande variabilidade da informação extraída a partir de prontuários. As razões dessa variabilidade são inúmeras, duas de maior destaque: o freqüente rodízio do profissional que atende às sucessivas consultas, e o fato de que, na medida em que o paciente é atendido em uma especialidade, a anamnese é mais centrada nos aspectos desta e, portanto, menos atenta às manifestações de outros aparelhos e sistemas. Nesta fase, foi possível constatar que independentemente da afecção, 13 de 14 casos investigados exibiram número de sintomas 2 a 8 vezes superior na entrevista com questionário em relação ao encontrado no levantamento com prontuários.

$\mathrm{Na}$ segunda fase, em que foram investig ados 99 indivíduos, os resultados obtidos foram extraídos exclusivamente do questionário/ entrevista, e estão representados na Tabela 2. As diferenças de prevalência dos sintomas exibidos variaram em função da afecção, já que cada uma tem seu próprio grau de agressão e sítios anatômicos preferenciais de envolvimento.

O cadastro sintomático da ESP mostrou predominância de sintomas referentes ao sistema digestório proximal. Disfagia, pirose, regurgitação, azia, plenitude gástrica atingiram percentuais acima de $40 \%$ dos casos. Impressionou a descrição de incontinência fecal em $27 \%$ dos pacientes. Embora admitido o comprometimento anor retal na $\operatorname{ESP}^{(10,35)}$, a incontinência fecal é raramente citada por outros autores. Acredita-se ter sido a maneira como foram conduzidas as entrevistas, que conseguiu contornar a natural inibição dos indivíduos em revelar a sua existência, permitindo, por outro lado, melhor conhecimento da sua real dimensão. Constipação foi manifestação comum, presente em 35\% dos pacientes. Diar réia ocorreu em 11,5\% dos casos e tem sido muitas vezes associada a supercrescimento bacteriano e distúrbios motoras do delg ado ${ }^{(8,29,33)}$

Tal como no presente estudo, a literatura registra elevado comprometimento do sistema digestório na ESP, variando entre $50 \%$ e $85 \%(4,18,24,26,34)$. Os sintomas relatados assemelham-se aos aqui catalogados; a frequiência com que cada um deles comparece, é contudo pouco referida, exceção dos esofágicos, ao redor de $75 \%$ nas diferentes casuísticas ${ }^{(19,26,28,34)}$. Os demais sintomas são citados de forma genérica. Essa escassez de detalhes inviabilizou comparações com os resultados do presente estudo, particularmente em relação às manifestações colorretais, motivo de persistentes controvérsias entre os que acreditam na sua presença freqüente ${ }^{(8,28,33,35)} \mathrm{e}$ os que dela divergem ${ }^{(26)}$. A controvérsia é alimentada pela elevada ocor rência e inespecificidade dos sintomas constipação e estufamento na população geral. Por outro lado, é impossível ignorar que as lesões do delg ado e grosso da ESP poderiam ser a origem primária de tais sintomas. Ademais, a frequiência com que eles foram encontrados é indiscutivelmente mais alta na ESP do que na população geral. Situação paradoxal encontrada em alguns pacientes foi a existência de lesão sem sintoma correspondente, por exemplo, ausência de disfagia em acometidos de alterações motoras do esôfago detectadas pelo exame manométrico. Outros autores têm feito constatações parecidas, sem explicação clara para elas ${ }^{(24,25,26)}$. A dissociação entre alteração anátomo-funcional e sintomas pode ser a explicação para a subestimativa do acometimento do sistema digestório por essa doença.

Na PM/DM, o número de sintomas gastrointestinais foi bastante expressivo. O segmento digestivo proximal apresentou o maior número de manifestações. Ressalta-se o acometimento correspondente à faringe e ao cricofaríngeo, gerando sensação de engasgo em $75 \%$ dos casos. Disfagia, pirose, estufamento e constipação também compareceram em elevados percentuais. A literatura destaca a disf agia e faz apenas menção superficial às outras manifestações ${ }^{(6,32)}$. Contudo, alguns estudos sublinham o comprometimento difuso do sistema digestório pela PM/DM ${ }^{(1,12,23,25)}$, caracterizado por esvaziamento esofágico lento, refluxo g astroesofágico e hérnia hiatal ${ }^{(1,12)}$, esvaziamento gástrico retardado $^{(12)} \mathrm{e}$ alteração da motilidade intestinal ${ }^{(1,23,32)}$. Desta forma, surpreende a escassez de sintomas descritos na literatura. É possível que a diferença com os resultados deste estudo decor ra da metodologia de pesquisa dos sintomas.

A casuística de DMTC da presente série foi reduzida, cinco no total, o que enfraquece o peso de qualquer conclusão. Entretanto, decidiu-se incluí-los nos resultados como contribuição ao estudo daquela doença, reconhecidamente de baixa prevalência ${ }^{(2)}$. Por tratar-se de condição em que se imbricam aspectos de várias DDTC, os sintomas expressam uma mistura das manifestações de todas elas. Conseqüentemente, foi obser vada presença superior a $50 \%$ de disfagia orofaríngea e esofágica, assim como de pirose e regurgitação. Plenitude gástrica e estufamento abdominal também foram queixas majoritárias. Incontinência fecal apresentou valores próximos aos encontrados na ESP. Para cotejar os resultados deste estudo com os da literatura, considerou-se como limitação o fato desta ser bastante rarefeita e concentrar atenção apenas nas manifestações esofágicas da DMTC ${ }^{(5,9)}$. Contudo, vários trabalhos reconhecem que o trato gastrointestinal pode ser extensamente afetado ${ }^{(1,2,20)}$. Em um desses ${ }^{(20)}$, os autores mencionam outros sintomas de menor ocorrência: dispepsia (20\%), diarréia (8\%) e constipação (5\%). Dor abdominal, presente 
em $20 \%$ dos pacientes desta série, tem sido atribuída na literatura a distúrbio motor intestinal ou vasculite. Infelizmente, entretanto, não foram encontrados estudos mais completos descrevendo o estado funcional dos diferentes segmentos digestivos na DMTC.

A literatura afirma que manifestações gastrointestinais estão presentes em mais de $50 \%$ dos portadores de $\operatorname{LES}^{(7,21,27)}$. Nos 21 casos aqui analisados, mais da metade apresentou náusea, pirose, regurgitação e plenitude. Dor abdominal também alcançou elevada cifra (33\%), assim como diaréia (28\%) e constipação (28\%). Foi surpresa a freqüência relatada de incontinência fecal, 19\%. Na literatura, os sintomas mais citados são náusea, vômito, dispepsia e dor abdominal $^{(32,36)}$. Outros, menos relacionados, são disfagia, pirose, diarréia e íleo paralítico ${ }^{(1,7,21)}$. A maior par te deles tem sido atribuída à vasculite, que pode acometer todo o sistema digestório, determinando alterações motoras, erosões e perfurações ${ }^{(1,21,36)}$. Estudos funcionais do trato gastrointestinal no LES revelam distúrbios motores esofágicos e intestinais ${ }^{(1,9,31)}$. Talvez por ser uma doença com comprometimento severo de múltiplos órgãos vitais, o estudo dos sintomas digestivos e seus mecanismos subjacentes têm merecido pouca atenção e permanecem mal conhecidos no LES.

Das DDTC, AR foi a que apresentou menor número de queixas digestivas. Nela, a maioria dos sintomas afetou menos de $20 \%$ dos entrevistados. Chama a atenção, contudo, a elevada taxa de disfagia encontrada - $31 \%$ - achado pouco valorizado na literatura ${ }^{(1,32)}$, a despeito de alteração da motilidade esofágica ser relatada em mais de $30 \%$ dos portadores de $\mathrm{AR}^{(13,16,30)}$. Distúrbios motores de outros segmentos do trato gastrointestinal também têm sido referidos ${ }^{(1,11,17)}$ e poderiam ser responsáveis por manifestações, como plenitude e constipação. Ao se comparar os resultados do presente estudo com os de outros autores, foi possível verificar não só a parcimônia de trabalhos sobre repercussões da AR no tubo digestivo, mas a antigüidade desses trabalhos ${ }^{(30,31)}$, alguns realizados três a quatro décadas atrás e, no entanto, continuamente citados na maioria das revisões. Estudos recentes, usando recursos atualizados, quase inexistem, prejudicando assim não só a reavaliação dos trabalhos antigos, como limitando a comparação de resultados com trabalhos atuais como o presente. $\mathrm{O}$ que se sobressai na maioria das revisões ou livros textos consultados é a tendência repetitiva em se considerar os sintomas da AR como basicamente devidos aos efeitos dos medicamentos analgésicos e antiinflamatórios. Mas será realmente esta a única ou causa predominante de tais sintomas?

Finalmente, algumas conclusões podem ser sugeridas pelos achados do presente trabalho. Primeira, a quantidade de sintomas gastrointestinais encontrados nas DDTC é expressiva. Segunda, a incontinência fecal ocorre com frequiência significativa. Terceira, cadastro de sintomas por intermédio de questionários predefinidos aparentemente garante maior abrangência e reprodutibilidade dos dados obtidos. Quarta, a escassez de trabalhos anteriores e atuais sobre as manifestações digestivas das DDTC prejudicou comparação adequada com os resultados desta série. E quinta, é recomendável a reavaliação dos resultados dos trabalhos realizados no passado usando recursos clínico-laboratoriais contemporâneos.

Machado WM, Freire BFA, Rocha OM,Azamb uja CAP, Oliveira MEC. Proposal of a questionnaire for prevalence's characterization of the digestive symptoms in the connective tissue diseases. Arq Gastroenterol 2004;41(1):64-70.

ABSTRACT - Background - Connecti ve tissue diseases may damage multiple organic systems, including digestive system. In this one, the deg ree of injury vary according to the associated disease. Despite the significant frequency of gastrointestinal involvement, there are few studies characterizing the prevalence of digestive symptoms in connective tissue diseases. Furthermore, most of the studies available are less detailed and based in personal experiences or reviews of records. Aim - To establish a reliable list of gastrointestinal symptoms found in the progressive systemic sclerosis, rheumatoid arthritis, polymyositis/dermatomyositis, mixed connective tissue disease and systemic lupus erythematosus, through a medical interview and a predefined questionnaire of symptoms. Patients and Methods - There were studied 99 patients, $90 \%$ females, mean age 45 years. The whole group were composed of 35 rheumatoid arthritis, 26 progressive systemic sclerosis, 21 systemic lupus erythematosus, 12 polymyositis/dermatomyositis and 5 mixed connective tissue disease. Each patient was submitted to an inter view with a well trainned doctor and answered a structured questionnaire, containing 17 questions. Results - It was found a high prevalence of digestive symptoms in all five connective tissue diseases searched. Many of them were present in more than 50\% of the patients. Called special attention the detection of some manifestations neglected by the literature like, for example, fecal incontinence. Also, disagreeing with other authors, was the finding of multiple gastrointestinal manifestations associated with rheumatoid arthritis. It was particularly surprising the occurrence of dysphagia in one third of the rheumatoid ar thritis group. Conclusions - The connective tissue diseases are usual causes of many gastrointestinal complaints. The use of an inter view plus predef ined questionnaire seems a very effective way to identify and characterize symptoms and is even sometimes able to uncover features unknown before. Finally, the lack of studies, specially updated studies, did not allow more comprehensi ve comparisons.

HEADINGS - Mixed connective tissue disease. Lupus erythematosus, systemic. Scleroderma, systemic. Arthritis, rheumatoid. Gastrointestinal diseases. Questionnaires. 


\section{REFERÊNCIAS BIBLIOGRÁFICAS}

1. Bailey M, Chapin W, Licht H, Reynolds JC. The effects of vasculitis on the gastrointestinal tract and liver. Gastroenterol Clin North Am 1998;27:747-82.

2. Bennett RM, O'Connell DJ. Mixed connective tissue disease: a clinicopathological study of 20 cases. Semin Arthritis Rheum 1980;10:25-51.

3. Burt RW, Berenson MM, Samuelson CO, Cathey WJ. Rheumatoid vasculitis of the colon presenting as pancolitis. Dig Dis Sci 1983;28:183-8.

4. Cohen S, Laufer I, Snape Jr W, Shiau Y, Levine GM, Jimenez S. The gastrointestinal manifestations of sclerodema: pathogenesis and management. Gastroenterology 1980;79:155-66.

5. Dantas RO, Villanova MG, Godoy RA. Esophageal dysfunction in patients with progressive systemic sclerosis and mixed connective tissue diseases. Arq Gastroenterol 1985;22:122-6.

6. DeVere R, Bradley WG. Polymyositis: its presentations, morbidity and mortality. Brain 1975;98:637-66.

7. Dubois EL,Tuffanelli DL. Clinical manifestations of systemic lupus erythematosus. JAMA 1964;190:104-11.

8. Greydanus MP, Camilleri M. Abnormal postcibal antral and small bowel motility due to neuropathy or myopathy in systemic sclerosis. Gastroenterology 1989;96:110-5.

9. Gutierrez F, Valenzuela JE, Ehresmann GR, Quismorio FP, Kitridou RC. Esophageal dysfunction in patients with mixed connective tissue diseases and systemic lupus erythematosus. Dig Dis Sci 1982;27:592-7.

10. Hamel-Roy J, Devroede G, Arhan P, Tetreaulte L, Duranceau A, Menard HA. Comparative esophageal and anorectal motility in scleroderma. Gastroenterology 1985;88:1-7.

11. Henriksson AEK, Blomquist L, Nord CE, Midtvedt T, Uribe A. Small intestinal bacterial overgrowth in patients with rheumatoid arthritis. Ann Rheum Dis 1993;52:503-10.

12. Horowitz M, McNeil JD, Maddern GJ, Collins PJ, Shear man DJC. Abnor malities of gastric and esophageal emptying in polymyositis and dermatom yositis. Gastroenterology 1986;90:434-9.

13. Janssen M, Dijkmans BAC, Lamers CBHW. Upper gastrointestinal manifestations in rheumatoid arthritis patients: intrinsic or extrinsic pathogenesis? Scand J Gastroenterol 1990;25 Suppl 178:79-84

14. Katza DA, Reynolds JC, Saul SH, Plotkin A, Lang CA, Ouyang A, Jimenez S, Cohen S. Barrett's metaplasia and adenocarcinoma of the esophagus in scleroder ma. Am J Med 1987;82:46-52.

15. Klein HA, Wald A, Graham TO, Campbell WL, Steen VD. Comparative studies of esophageal function in systemic sclerosis. Gastroenterology 1992;102:1551-6.

16. Lapadula G, Muolo P, Semeraro F, Covelli M, Brindicci D, Cuccorese G, FrancavillaA, Pipitone V. Esophageal motility disorders in the rheumatic diseases: a review of 150 patients. Clin Exp Rheumatol 1994;12:515-21.

17. Ljubich P, Parkman HP, Fisher RS, Sorokin JJ, Conaway DC. Diffuse gastrointestinal dysmotility in a patient with rheumatoid arthritis. Am J Gastroenterol 1993;88:1443-5.

18. Lock G, Holstege A, Lang B, Scholmerich J. Gastrointestinal manifestations of progressive systemic sclerosis. Am J Gastroenterol 1997;92:763-71.
19. Maddern GJ, Horowitz M, Jamieson GG, Chatterton BE, Collins PJ, RobertsThomson P. Abnormalities of esophageal and gastric emptying in progressive systemic sclerosis. Gastroenterolo gy 1984;87:922-6.

20. Marshall JB, Kretschmar JM, Gerhardt DC, Winship DH, et al. Gastrointestina manifestations of mixed connective tissue disease. Gastroenterology 1990;98:1232-8.

21. Ma yer LF. Gastrointestinal manifestations of systemic lupus erythematosus. In Lahita RG, editor. Systemic lupus erythematosus. New York: John Wiley; 1987. p.187-213.

22. Menin RC, Urizar MG, Pirani WM, Barbosa VP, Sato WI, Atra E, Andrade LEC Peritonite lúpica crônica com ascite - relato de caso e revisão da literatura. Rev Bras Reumatol 1993;33:114-8.

23. Plotz PH, Dalakas M, Leff RL, Love LA, Miller FW, Cronin ME. Cur rent concept in the idiopathic inflammatory myopthies: polymyositis, dermatomyositis and related disorders. Ann Intern Med 1989;111:143-57.

24. Poirier TJ, Rankin GB. Gastrointestinal manifestations of progressive systemic scleroder ma based on a review of 364 cases. Am J Gastroenterol 1972;58:30-44.

25. Rio Nobre MC, Machado WM. Manifestações gastrintestinais das doenças reumatológicas. GED Gastroenterol Endosc Dig 1993;12:140-8.

26. Rose S, Young MA, Reynolds JC. Gastrointestinal manifestations of scleroderma Gastroenterol Clin Nor th Am 1998;27:563-94.

27. Schur PH. Systemic lupus erythematosus and related syndromes. In: Kelley WN Harris ED, Ruddy S, Sledge CB, editors. Textbook of Rheumatology. 3rd ed. Philadelphia: WB Saunders; 1989. p.1101-29.

28. Sjogren RW. Gastrointestinal motility disorders in scleroderma. Arthritis Rheum 1994;37:1265-82.

29. Soudah HC, Hasler WL, Owyang C. Effect of octreotide on intestinal motility and bacterial overgrowth in scleroderma. N Engl J Med 1991;325:1461-7.

30. Sun DCH, Roth SH, Mitchell CS, England DW. Upper gastrointestinal disease in rheumatoid ar thritis. Am J Dig Dis 1974;19:405-10.

31. Tatelman M, Keech MK. Esophageal motility in systemic lupus erythematosus, rheumatoid ar thritis, and scleroderma. Radiology 1966;86:1041-6.

32. Weber JR, Ryan JC. Rheumatologic and collagen diseases. In: Feldman M, Scharsmidt BF, editors. Gastrointestinal and liver diseases. 6th ed. Philadelphia: WB Saunders; 1998. p.422-5.

33. Wegener M, Adamek RJ, Wedmann B, Jergas M, Altmeyer P. Gastrointestinal transit through esophagus, stomach, small and large intestine in patients with progressive systemic sclerosis. Dig Dis Sci 1994;39:2209-15.

34. Weston S, Thumshirn M, Wiste J, Camilleri M. Clinical and upper g astrointestinal motility features in systemic sclerosis and related disorders. Am J Gastroenterol 1998;93:1085-9.

35. Whitehead WE, Taitelbaum G, Wigley FM, Schuster MM. Rectosigmoid motility and myoelectric activity in progressive systemic sclerosis. Gastroenterology 1989;96:428-32.

36. Zizic TM, Shulman LE, Stevens MB. Colonic perforations in systemic lupus erythematosus. Medicine (Baltimore) 1975;54:411-26.

Recebido em 20/3/2003 Aprovado em 25/9/2003 